\title{
Forum
}

\section{Schwerpunkt: Politik gegen Armut und für nachhaltige Entwicklung}

Das Jahr 2015 ist ein entscheidendes Jahr im Kampf gegen Armut und für nachhaltige Entwicklung: es ist das Zielerreichungsjahr der Millenniums-Entwicklungsziele. Hierbei handelt es sich um ein Bündel von Vorhaben, die im Jahr 2000 infolge des Millenniums-Gipfels der Vereinten Nationen erarbeitet wurden.

Das Hauptaugenmerk der Entwicklungsziele liegt auf der Armutsbekämpfung. Bis 2015 - so die Zielvorgabe - solle die Armut in der Welt halbiert werden. Armut wird dabei weit gefasst und nicht mehr nur auf Einkommensarmut beschränkt, sondern auch als Mangel an Teilhabechancen interpretiert. Damit geriet nicht nur Armut etwa in Entwicklungs- und Schwellenländern in den Fokus, sondern verstärkt auch in der westlichen Welt, denn gerade hier äußert sich Armut zunehmend in fehlenden Möglichkeiten der Teilhabe am sozialen, kulturellen oder politischen Leben.

Ein zweiter Schwerpunkt der Millenniums-Strategie liegt auf den Feldern Umweltschutz und Nachhaltigkeit. Derzeit mehr als sieben Milliarden Menschen Tendenz steigend - verbrauchen in immer schnellerem Maße die begrenzten natürlichen Ressourcen der Erde. Vom Menschen induzierte Umweltschäden, Klimaveränderungen, Naturkatastrophen und Hungersnöte nehmen zu und treffen wiederum vor allem die Ärmsten der Armen in den Ländern des globalen Südens. Nachhaltigkeit - so die UN - muss deshalb mehr denn je die Maxime verantwortungsvoller Politik sein.

Aufgrund des so zentralen Jahres 2015 steht das folgende Forum unter dem Thema „Politik gegen Armut und für nachhaltige Entwicklung“. Christoph Butterwegge beleuchtet theoriegeleitet, wieso die Bundesregierung die Aufgabe der Armutsbekämpfung seit Jahren vernachlässigt. Gerhard Bosch analysiert aus dem Blickwinkel der politischen Systemforschung, inwieweit ein Mindestlohn ein wirksames Mittel im Kampf gegen Armut sein kann. Clara Brandi und Dirk Messner widmen sich aus der internationalen Perspektive schließlich der Frage, was hinsichtlich einer nachhaltigen Entwicklung nach 2015 auf die MillenniumsEntwicklungsziele folgen muss. 